INTERNATIONAL JOURNAL OF RESEARCHES IN BIOSCIENCES, AGRICULTURE AND TECHNOLOGY

(C) VISHWASHANTI MULTIPURPOSE SOCIETY (Global Peace Multipurpose Society) R. No. MH-659/13(N) www.vmsindia.org

\title{
AN IN SILICO STUDY OF ACTIVITY OF HYDROPHOBIC AMINO ACIDS AS POSSIBLE MOTIF STRUCTURES IN ANTIMICROBIAL PEPTIDES OF DIVERGENT ORIGINS
}

\author{
D. Begde \\ Dr. Ambedkar College, Deeksha bhoomi, Nagpur, (MS) India
}

\begin{abstract}
Antimicrobial peptides (AMPs) are widespread in nature and are being employed by a diverse group of organisms, from bacteria to humans for exterminating microbial pathogens. Although having diverse origins, different structures and unique modes of action, all the AMPs share a common feature and that is, till date there are almost no reports suggesting the development of microbial resistance against these peptides. The present study uses a mathematical graph theoretical approach and the information from an updated AMP database-APD2 (http://aps.unmc.edu/AP/main.php)-to demonstrate the recurrence of some hydrophobic amino acid residues (motifs) within different classes of AMPs.
\end{abstract}

Key words: Sequences; Protein motifs; databases; biochemical networks

\section{Introduction:}

Exterminating microbial pathogens by utilizing specially designed antimicrobial peptides (AMPs) is an interesting strategy employed by nature. Extremely widespread production of these peptides throughout bacterial, fungal, plant and animal kingdom could be taken as a proof of their success.

Depending upon their primary sequence homology the AMPs are divided into several different classes. Most of the members belonging to one class have similar origins with some minor exceptions. But strikingly, all the AMPs across the various different classes share a common feature and that is, till date there are almost no reports suggesting the development of microbial resistance against these peptides.

In the present work, we demonstrate by using BLAST $\mathrm{P}$, the protein sequence alignment tool, that in spite of belonging to different classes many of these AMPs do show a remarkable homology in the content of a particular category of their amino acid residues. These amino acids are typically hydrophobic in nature, and might be present as a block of two or as distantly interacting single residues at any position in the peptide sequence. Their presence was consistently observed within different classes of AMPs. Some of the amino acid combinations that were studied and scanned for were $\mathrm{TG}, \mathrm{HV}, \mathrm{LC}, \mathrm{AL}, \mathrm{GL}$, etc. in increasing frequency of occurrence. Moreover, all the AMPs showing the presence of these amino acids had distinctly divergent origins which included peptides from bacteria, fungi, invertebrates, amphibians, plants and mammals.

We particularly focus on and address the issue of presence as well as frequency of appearance of some identifiable blocks of hydrophobic amino acid as pairs or as singleton in the linear sequence of amino acids that form the primary structure of proteins. We scan the retrieved sequences for the appearance of either the amino acid pairs, or even solitary ones of the hydrophobic residues identified in the course of this work, and postulate that some of the characters of the AMPs in which these appear, are induced due to the presence of such special blocks that assume importance enough to be labelled as one of the fundamental building blocks of the amino acid sequence.

Most of the AMPs essentially have hydrophobic amino acids which are responsible for their antimicrobial activity. The peptides selected for the present study preferentially lack the secondary structure which might otherwise require polar/charged-polar amino acids at specific positions. These polar amino acids are incorporated so that they could be modified or crosslinked to provide the peptide with a specific secondary structure essential for its activity.

For our present work, we have selected some hydrophobic amino acids whose mere presence irrespective of their position and hence independent of peptide secondary structure, is enough for the peptides' activity. The amino acids selected for our study were Alanine (A), Leucine (L), Valine (V), Isoleucine (I). These four amino acids have similar degree of hydrophobicity. In addition to these Glycine $(G)$ which is neither hydrophilic nor hydrophobic was also considered as a special case. Amino acids Cystein $(\mathrm{C})$, Histidine $(\mathrm{H})$ and Threonine (T) belonging to less polar category, but still somewhat capable of undergoing hydrophobic interactions were also included for screening.

APD2, the updated AMP database was used for scanning of the antimicrobial peptides 
which have the above amino acids, for the present study. The availability of detailed molecular data via high throughput technologies allows us a reconstruction of the amino acid sequence structure at the system level. We apply graph theory for modelling the system constituting the protein primary sequence, and try to gain and insight into the significance of the presence and frequency of the selected hydrophobic amino acid blocks within the AMP sequences.

\section{Graph theory}

Various cellular functions of an organism are carried out through a complex network of interactions among the specific cellular components and factors designed and responsible for a given process 1 . Networks are the topological aspects of a graph, and have been used in the literature by scholars to study and describe processes such as protein - protein interaction, prediction of conditional gene essentiality, transcriptional regulatory networks and metabolic pathways, to mention few of the important issues current in the scholarship 2, $3,4,5,6,7,8,9$.

Network motifs are patterns of interactions occurring in complex networks, which occur with a remarkably high frequency compared to a randomized network. These motifs could be viewed as the vertices of a graph, with the interactions among them being mediated by the edges, thus constituting the basic building blocks of networks 10, 11, 12 .

In this paper we consider the undirected graph $G$ comprising the triple $G=(V, E, \gamma)$, where the amino acids constituting the peptide sequence are represented as vertices $v_{i}$ and comprise the set $V$ while the interaction between any two amino acids is represented by an edge $e_{i}$ and comprise the set $E$, with $E \cap V=\phi$. The mapping $\gamma: E \rightarrow V \times V$, assigns an edge to any two specific vertices by the definition $e_{i} \mapsto \gamma\left(e_{i}\right)=\left\{v_{i}, v_{j}\right\}$. The vertices $v_{i}$ and $v_{j}$ share an edge $e_{i}$ and are adjacent vertices. The set $E=\left\{e_{1}, e_{2}, \ldots, e_{n}\right\}, n \in Z_{+}$is a finite collection of interactions between the amino acids in pairs, and therefore the set of edges $E \subseteq[V]^{2}$, a two-element subset of the set of vertices $V$. A graph $G$ is connected if there exist paths (a sequence of adjacent vertices and edges connecting these) in $G$ between any two vertices $\in V . \quad G^{\prime}=\left(V^{\prime}, E^{\prime}, \gamma^{\prime}\right)_{\text {with }}$ $V^{\prime} \subseteq V, E^{\prime} \subseteq E$, and $\gamma_{\text {a restriction on }}^{\prime} \gamma_{\text {to }}$ $E^{\prime}$ is a subgraph of graph $G$.

A motif is a connected subgraph of the graph $G$ that represents the primary (linear) sequence structure of the amino acids forming a protein or a peptide. A motif, in the present context, could thus be understood as a basic graph template of biologically interacting amino acid vertices that acts as a fundamental building block for the peptide sequence in conferring the protein/peptide its functional characteristics $13,14,15$.

In the present work, we focus on the two-vertex graphs formed by pairs of amino acids, in the primary sequence of AMPs. Irrespective of the actual locus of these amino acids in the peptide sequence, the mutual interactions between any two of them or the interactions of a lone amino acid with its neighbours in the sequence imply the existence of edges between as well as to and from these vertices. Our principal objective in this work is to establish the importance of these motifs within the AMPs studied, by contextualizing the presence of these graphs vis-a-vis the lethality of the AMPs.

A match of a motif (amino acid(s)) $G^{\prime}$ within a target graph (the protein) $G_{\text {is a graph }}$ $G^{\prime \prime}$ which is also a subgraph of $G$, and is isomorphic to the motif $G^{\prime}$. The frequency of a motif is the number of its matches in the target graph 16 .

\section{Procedure}

The present work is based on in silico data, retrieved from the APD2 database http://aps.unmc.edu/AP/main.php.

The following is the tabulation of the frequencies of amino acid motifs occurring as pairs as well as split single residues in the selected AMPs:

It should be noted that in Table 1 the total number of antibacterial peptides (1179) available in the database was used to calculate the match percentage. If the number of antifungal and antiviral peptides is also added the total becomes 1731 however this number is not considered because most of the peptides belonging to antifungal and antiviral class also exhibit antibacterial activity.

Table 1 shows an appreciably higher frequency of match for the hydrophobic amino 
acid blocks, both as two-vertex as well as onevertex motifs. It is noteworthy to focus on the GL motif, which is seen to have the highest frequency of match within the peptide sequences. The frequency of this graph when split into two separate amino acid vertices G-L (single-vertex motifs) is still significantly higher at $81.5 \%$. The frequencies for some other motifs with similar degree of hydrophobicity as GL are also seen to be appreciably high, particularly as one-vertex motifs in the selected AMPs. Moreover when the interaction of selected amino acids within themselves was determined in the peptide sequence as single vertex motifs the frequency recorded was even higher (eg. G-G etc.).

The peptide sequences obtained from the database were further short listed on the basis of their content of the four hydrophobic amino acids (and/or Glycine) identified above, either as two-vertex or one-vertex motifs. The objective was to find those amino acid residues which were common within every scanned result, as well as those which were unique to a single query.

From these peptides few of the shortest sequences were selected for our work, because being the shortest, these peptides would possess the minimal essential amino acids to retain their antimicrobial activity, as also would show low propensity for folding. While selecting the short peptides, those belonging to different and distant origins were preferred in order to invoke a genetic diversity in the selection, and then to identify possible motifs in these peptides from diverse origins. The selected peptides with their origins in parentheses are listed below:

1. GLLKRIKTLL-NH $\mathbf{N H}_{2}$ Anoplin (insect, invertebrates, animals),

2. PFKLSLHL-NH $\mathbf{N H}_{2}$ Jelleine-I (honeybees, insect, invertebrates, animals),

3. RLCRIVVIRVCR Bactenecin (Cyclic dodecapeptide, cow cathelicidin, animals),

4. GLLDIVKKVVGAFGSL-NH2 Aurein 2.1 (frog, amphibians, animals),

5. SVAGRAQGM Cn-AMP1 (Cocos nucifera L. antimicrobial peptide 1 , plants).

As can be seen from their amino acid sequence not all the selected peptides have all the hydrophobic amino acids of interest. Anoplin and Jelleine are from insect origin, Bactenecin from mammalian origin, Aurein from amphibian while Cn-AMP1 from plant origin (and a few more are given in the table 2). Although from diverse origins, the hydrophobic amino acid motifs comprise at least around $50 \%$ of the constitution of each of the above chosen peptide sequences.

\section{Discussion and Inference:}

The amino acid substitution studies within all the above selected peptides have conclusively proved the importance of amino acid motifs in the peptides in terms of their lethality (refer table 2 for the entire discussion hereafter). Anoplin is a decapeptide amide, GLLKRIKTLL- $\mathrm{NH}_{2}$ derived from the venom sac of the solitary spider wasp, Anoplius samariensis. Complete alanine scan of this peptide has proved that the replacement of any polar amino acid by " $A$ " within its sequence increases the activity of the resulting peptide in most of the cases. Moreover, it is also reported that the replacement of the $5^{\text {th }}$ amino acid arginine (R) with any of the hydrophobic amino acid remarkably enhances the activity of the peptide. Interestingly, however, replacement of any previously existing hydrophobic amino acid with any other polar amino acid markedly reduces the activity of the peptide ${ }^{17}$. This similar observation is also recorded for the next peptide Jelleine-I which along with 3 other homologous AMPs forms an integral part of the "royal jelly" produced by honey bees, which is the principle food of the queen honey bee. The other three Jelleine peptides differ only at their first amino acid from Jelleine-I where they have an extra amino acid, otherwise the sequence is exactly same as Jelleine-I. The exception here is of Jelleine-IV which lacks the last Leucine residue and thus is reduced to the same size as that of Jelleine-I ( 8 amino acids). But this loss of one terminal leucine residue results in a lethal loss of activity within Jelleine-IV. This observation clearly demonstrates the importance of the terminal leucine residue within the Jellein peptides ${ }^{18}$.

Bactenecin (also called bovine dodecapeptide) from bovine neutrophils is a cyclic dodecapeptide. However in addition to its naturally occurring cyclic form several linear derivatives were synthesized. Both within cyclic and linear derivatives those peptides with A, L or $\mathrm{V}$ substitution for polar amino acids proved to be beneficial for the peptide's activity, while the reverse substitutions lead to loss of activity in most of the situations ${ }^{19}$. Similar observations were recorded for the other two study peptidesAureins and Cn-AMP1. Aurein peptides are amphipathic and a-helical peptides; Aurein 1.2 with only 13 amino acid residues, it is one of the smallest amphibian peptides so far reported. 
Although Aureins are amphipathic it is their hydrophobicity that is responsible for their antimicrobial activity ${ }^{20-21}$. Same is true for the green coconut water peptide Cn-AMP1 which is the most active peptide within the collection of three AMPs from the same source, named CnAMP2 and 3 and which differs from Cn-AMP1 just in their proportion of hydrophobic amino acids $^{22}$. One of the most important evidences about the vitality of our selected hydrophobic amino acids in imparting microbicidal property to AMPs comes from the example of another amphibian peptide uperin 3.6 isolated from the Australian toadlet Uperoleia mjobergii. With only 17 amino acids it is one of the smallest of known amphibian AMPs. Although small it has been reported to be very potent against even the most deadly of all bacterial pathogens including methicillin-resistant staphylococci, and vancomycin-resistant enterococci 23 . Interesting feature of this peptide is its amino acid content. Ten of its amino acids are hydrophobic out of which only one is terminal phenylalanine which is aminated, while others include V,I,L,A and in addition to these there is one $\mathrm{G}$ at the $\mathrm{N}$ terminal and six other polar amino acids ${ }^{23}$. With this amino acid composition it could be very well stated that the secret of uperin 3.6's potency is largely because of its hydrophobic amino acid composition.

From the above discussion, we infer that since the selected amino acid motifs appear in AMPs drawn from diverse origins, it is possible that there may exist an evolutionary pressure to maintain these specific motifs for the significant activity levels of the peptides. These motifs then should be evolutionarily conserved should have identifiable orthologs across the diverse organisms.

Table 1: Occurrence frequency of selected amino acids as single or two vertex motifs.

\begin{tabular}{|c|c|c|c|}
\hline Amino acid motif & Nature & Match frequency (out of 1179) & Match \% \\
\hline TG & Partially hydrophobic & 134 & 11.4 \\
\hline GT & Partially hydrophobic & 132 & 11.2 \\
\hline LC & hydrophobic \& polar & 113 & 9.6 \\
\hline $\mathrm{CL}$ & Polar \& hydrophobic & 90 & 7.6 \\
\hline $\mathrm{HV}$ & polar \& hydrophobic & 71 & 6.0 \\
\hline $\mathrm{VH}$ & Hydrophobic \& polar & 30 & 2.5 \\
\hline $\mathrm{AL}$ & Hydrophobic & 215 & 18.2 \\
\hline LA & Hydrophobic & 236 & 20.0 \\
\hline $\mathrm{AV}$ & Hydrophobic & 133 & 11.3 \\
\hline VA & Hydrophobic & 180 & 15.3 \\
\hline $\mathrm{AI}$ & Hydrophobic & 192 & 16.3 \\
\hline IA & Hydrophobic & 198 & 16.8 \\
\hline VL & Hydrophobic & 187 & 15.9 \\
\hline $\mathrm{LV}$ & Hydrophobic & 143 & 12.1 \\
\hline IL & Hydrophobic & 173 & 14.7 \\
\hline LI & Hydrophobic & 132 & 11.2 \\
\hline IV & Hydrophobic & 110 & 9.3 \\
\hline VI & Hydrophobic & 112 & 9.5 \\
\hline GL & Hydrophobic & 395 & 33.5 \\
\hline LG & Hydrophobic & 290 & 24.6 \\
\hline GA & Hydrophobic & 251 & 21.3 \\
\hline $\mathrm{AG}$ & Hydrophobic & 325 & 27.6 \\
\hline GI & Hydrophobic & 245 & 20.8 \\
\hline IG & Hydrophobic & 276 & 23.4 \\
\hline GV & Hydrophobic & 248 & 21.0 \\
\hline $\mathrm{VG}$ & Hydrophobic & 264 & 22.4 \\
\hline T-G/G-T & Hydrophobic & 655 & 55.5 \\
\hline $\mathrm{L}-\mathrm{C} / \mathrm{C}-\mathrm{L}$ & Hydrophobic & 470 & 39.9 \\
\hline $\mathrm{H}-\mathrm{V} / \mathrm{V}-\mathrm{H}$ & Hydrophobic & 364 & 32.6 \\
\hline L-A/A-L & Hydrophobic & 846 & 71.8 \\
\hline $\mathrm{A}-\mathrm{V} / \mathrm{V}-\mathrm{A}$ & Hydrophobic & 743 & 63.0 \\
\hline A-I/I-A & Hydrophobic & 786 & 66.7 \\
\hline V-L/L-V & Hydrophobic & 822 & 69.7 \\
\hline I-L/L-I & Hydrophobic & 890 & 75.5 \\
\hline $\mathrm{I}-\mathrm{V} / \mathrm{V}-\mathrm{I}$ & Hydrophobic & 781 & 66.2 \\
\hline G-L/L-G & Hydrophobic & 961 & 81.5 \\
\hline G-I/I-G & Hydrophobic & 904 & 76.6 \\
\hline G-A/A-G & Hydrophobic & 860 & 72.9 \\
\hline
\end{tabular}




\begin{tabular}{|l|l|l|l|}
\hline G-V/V-G & Hydrophobic & 860 & 72.9 \\
\hline G-G & Hydrophobic & 1078 & 91.4 \\
\hline L-L & Hydrophobic & 1046 & 88.7 \\
\hline I-I & Hydrophobic & 969 & 82.2 \\
\hline A-A & Hydrophobic & 921 & 78.1 \\
\hline V-V & Hydrophobic & 916 & 77.7 \\
\hline
\end{tabular}

Table 2: Amino acid sequences of different selected study group peptides and there derivatives with their respective Minimal Inhibition Concentration (MIC) values. Higher the MIC lower is the potency except for Ponericins where activity is represented in terms of zone of inhibition, and so, higher the value more is the potency.

\begin{tabular}{|c|c|c|c|c|}
\hline $\begin{array}{l}\text { S.N } \\
\text { o. }\end{array}$ & Name of Peptide & Sequence & \multicolumn{2}{|l|}{$\begin{array}{l}\text { MIC } \\
(\mu \mathrm{g} / \mathrm{ml})\end{array}$} \\
\hline I. & \multicolumn{2}{|c|}{ Anoplin (insect, invertebrates, animals) } & S.aureus & E.coli \\
\hline 1. & Anoplin & GLLKRIKTLL- $\mathrm{NH}_{2}$ & 13 & 26 \\
\hline 2. & ano-A1 & ALLKRIKTLL- $\mathrm{NH}_{2}$ & $>21$ & $>21$ \\
\hline 3. & ano-A2 & GALKRIKTLL- $\mathrm{NH}_{2}$ & $>43$ & $>43$ \\
\hline 4. & ano-A3 & GLAKRIKTLL- $\mathrm{NH}_{2}$ & $>38$ & $>38$ \\
\hline 5. & ano-A4 & GLLARIKTLL- $\mathrm{NH}_{2}$ & 28 & 16 \\
\hline 6. & ano-A5 & GLLKAIKTLL- $\mathrm{NH}_{2}$ & 10 & 5 \\
\hline 7. & ano-A6 & GLLKRAKTLL- $\mathrm{NH}_{2}$ & $>41$ & $>41$ \\
\hline 8. & ano-A7 & GLLKRIATLL- $\mathrm{NH}_{2}$ & 11 & 11 \\
\hline 9. & ano-A8 & GLLKRIKALL- $\mathrm{NH}_{2}$ & 8 & 16 \\
\hline 10. & ano-A9 & GLLKRIKTAL- $\mathrm{NH}_{2}$ & $>31$ & 49 \\
\hline 11. & ano-A10 & GLLKRIKTLA- $\mathrm{NH}_{2}$ & $>48$ & $>48$ \\
\hline II. & \multicolumn{2}{|c|}{ Jelleine (honeybees, insect, invertebrates, animals) } & & \\
\hline 12. & Jelleine-I & PFKISIHL- $\mathrm{NH}_{2}$ & 10 & 2.5 \\
\hline 13. & Jelleine-II & TPFKISIHL- $\mathrm{NH}_{2}$ & 15 & 15 \\
\hline 14. & Jelleine-III & EPFKISIHL- $\mathrm{NH}_{2}$ & 30 & 15 \\
\hline 15. & Jelleine-IV & TPFKISIH- $\mathrm{NH}_{2}$ & $\mathrm{R}$ & $\mathrm{R}$ \\
\hline III. & \multicolumn{2}{|c|}{$\begin{array}{l}\text { Bactenectin (cow cathelicidin, animals) } \\
\text { Cyclic peptides }\end{array}$} & & \\
\hline 16. & Bactenecin & RLCRIVVIRVCR & $32-64$ & 8 \\
\hline 17. & Bac R & $\boldsymbol{R} R L C R I V V I R V C R \boldsymbol{R}$ & 64 & 2 \\
\hline 18. & Bac P3R & RRRCPIVVIRVCR $\boldsymbol{R}$ & $>64$ & 2 \\
\hline 19. & Bac P3R-V & $\boldsymbol{R} \boldsymbol{R} R L C P I V \_I R V C R \boldsymbol{R}$ & $>64$ & 2 \\
\hline 20. & Bac 2I-NH 2 & RICRIVVIR_CIR- $\mathrm{NH}_{2}$ & 32 & 4 \\
\hline 21. & Bac P2R- $\mathrm{NH}_{2}$ & RLCPRVRIRVCR- $\mathrm{NH}_{2}$ & $>32$ & 4 \\
\hline 22. & Bac P1 & RLCRIVPVIRVCR & 64 & 32 \\
\hline 23. & $\mathrm{Bac} \mathrm{W}$ & RLCRIV WIRVCR & 4 & 8 \\
\hline \multirow[t]{2}{*}{24.} & Bac W2R & RRLCRIV WVIRVCR $\boldsymbol{R}$ & 2 & 2 \\
\hline & Linear peptides & & & \\
\hline 25. & $\begin{array}{l}\text { Linear } \\
\text { (reduced)Bactenecin }\end{array}$ & RLCRIVVIRVCR & $>64$ & 64 \\
\hline 26. & Lin Bac 2S- $\mathrm{NH}_{2}$ & RLSRIVVIRVSR- $\mathrm{NH}_{2}$ & 4 & 2 \\
\hline 27. & Lin Bac 1S- $\mathrm{NH}_{2}$ & RLSRIVVIRVCR- $\mathrm{NH}_{2}$ & 16 & 4 \\
\hline 28. & Lin Bac 2A- $\mathrm{NH}_{2}$ & RLARIVVIRVAR- $\mathrm{NH}_{2}$ & 4 & 4 \\
\hline 29. & Lin Bac P3R & RRRCPIVVIRVCRR & $>64$ & 8 \\
\hline 30. & Lin Bac P3R-V & 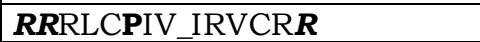 & $>64$ & 4 \\
\hline 31. & Lin Bac P1 & RLCRIVPVIRVCR & $>64$ & 16 \\
\hline 32. & Lin Bac W & RLCRIV WIRVCR & $>64$ & $>64$ \\
\hline 33. & Lin Bac W2R & $\boldsymbol{R}$ RLCRIV WVIRVCR $\boldsymbol{R}$ & $>64$ & $>64$ \\
\hline IV. & \multicolumn{3}{|c|}{ Cn-AMP1 (Cocos nucifera L. antimicrobial peptide 1, plants) } & \\
\hline 34. & Cn-AMP1 & SVAGRAQGM & 80 & 82 \\
\hline 35. & Cn-AMP2 & TESYFVFSVGM & 170 & 170 \\
\hline 36. & Cn-AMP3 & YCSYTMEA & 302 & 274 \\
\hline V. & \multicolumn{2}{|c|}{ Aurein (frog, amphibians, animals) } & & \\
\hline 37. & Aurein $1.2^{24}$ & GLFDIIKKIAESF & $\begin{array}{l}8^{\mathrm{a}} \\
32\end{array}$ & 256 \\
\hline 38. & Aurein 2.1 & GLLDIVKKVVGAFGSL & - & - \\
\hline 39. & Aurein 2.2 & GLFDIVKKVVGALGSL-CONH 2 & 15 & - \\
\hline 40. & Aurein 2.3 & GLFDIVKKVVGAIGSL-CONH $_{2}$ & 25 & - \\
\hline
\end{tabular}




\begin{tabular}{|c|c|c|c|c|}
\hline 41. & Aurein 2.4 & GLFDIVKKVVGTLAGL & - & - \\
\hline 42. & Aurein 2.5 & GLFDIVKKVVGAFGSL-NH ${ }_{2}$ & 206.25 & 49.5 \\
\hline 43. & Aurein 3.1 & GLFDIVKKIAGHIAGSI & - & - \\
\hline 44. & Aurein 3.2 & GLFDIVKKIAGHIASSI & - & - \\
\hline 45. & Aurein 3.3 & GLFDIVKKIAGHIVSSI & - & - \\
\hline VI. & \multicolumn{2}{|c|}{ Uperin (amphibians, toad, animals) } & & \\
\hline 46. & Uperin 2.1 & GIVDFAKKVVGGIRNALGI-OH & $>100$ & $>100$ \\
\hline 47. & Uperin 2.5 & GIVDFAKGVLGKIKNVLGI-OH & - & - \\
\hline 48. & Uperin 2.8 & GILDVAKTLVGKLRNVLGI-OH & $>100$ & $>100$ \\
\hline 49. & Uperin 3.5 & GVGDLIRKAVSVIKNIV_- $-\mathrm{NH}_{2}$ & 50 & $>100$ \\
\hline 50. & Uperin 3.6 & GVIDAAKKVVNVLKNLF-NH 2 & $\begin{array}{l}8^{a} \\
16\end{array}$ & 128 \\
\hline VII & \multicolumn{2}{|c|}{ Ponericin (ants, insects, invertebrates, animals) } & $\begin{array}{l}\text { Zone of } \\
(\mathrm{mm}) \text { Test } \\
0.5 \mathrm{mM}\end{array}$ & $\begin{array}{l}\text { Inhibition } \\
\text { Conc. 0.4- }\end{array}$ \\
\hline 51. & Ponericin G125 & $\begin{array}{l}\text { GWKDWAKKAGGWLKKKGPGMAKAAL } \\
\text { KAAMQ }\end{array}$ & 11.5 & 9 \\
\hline 52. & Ponericin G2 & $\begin{array}{l}\text { GWKDWLKKGKEWLKAKGPGIVKAALQ } \\
\text { AATQ }\end{array}$ & - & - \\
\hline 53. & Ponericin G3 & $\begin{array}{l}\text { GWKDWLNKGKEWLKKKGPGIMKAALK } \\
\text { AATQ }\end{array}$ & 7.5 & 8 \\
\hline 54. & Ponericin G4 & $\begin{array}{l}\text { DFKDWMKTAGEWLKKKGPGILKAAMA } \\
\text { AAT. }\end{array}$ & - & - \\
\hline 55. & Ponericin G5 & $\begin{array}{l}\text { GLKDWVKIAGGWLKKKGPGILKAAMAA } \\
\text { ATQ }\end{array}$ & - & - \\
\hline 56. & Ponericin G6 & $\begin{array}{ll}\text { GLVDVLGKVGGLIKKLLP- } & \mathrm{NH}_{2-}-\end{array}$ & 10 & - \\
\hline 57. & Ponericin G7 & GLVDVLGKVGGLIKKLLPG & - & - \\
\hline 58. & Ponericin L1 & LLKELWTKMKGAGKAVLGKIKGLL & - & - \\
\hline 59. & Ponericin L2 & LLKELWTKIKGAGKAVLGKIKGLL & 4.5 & 4 \\
\hline 60. & Ponericin W1 & WLGSALKIGAKLLPSVVGLFKKKKQ & 10 & 5 \\
\hline 61. & Ponericin W2 & WLGSALKIGAKLLPSVVGLFQKKKK_ & - & - \\
\hline 62. & Ponericin $\mathrm{W} 3$ des $\mathrm{K}$ & GIWGTLAKIGIKAVPRVISMLKKK_Q & 13 & 7 \\
\hline 63. & Ponericin W4 & GIWGTALKW GVKLLPKLVGMAQTKK_Q & 11.5 & 6 \\
\hline 64. & Ponericin W5 & FWGALIKGAAKLIPSVVGLF_KKKQ & 7.5 & 2 \\
\hline 65. & Ponericin W6 & FIGTALGI_ASAIPAIVKLF_K & 7 & - \\
\hline
\end{tabular}

It should be noted that in Table 2 Significance of letters in the peptide sequence is as follows:

Bold - Amino acid substitutions in the original sequence

Bold Italics - Additional amino acids in the original sequence

Underscore _- Missing/deleted amino acids from the original sequence.

And the significance of the superscript characters is as follows:

a - Methicillin Resistant S. aureus (MRSA)

Figure 1: Representation of covalently linked amino acid pair frequency in AMPs. The grey, blue and red bars indicate amino acid pairs with $<15 \%, 15-20 \%$ and $>20 \%$ occurrence frequencies in AMPs respectively.

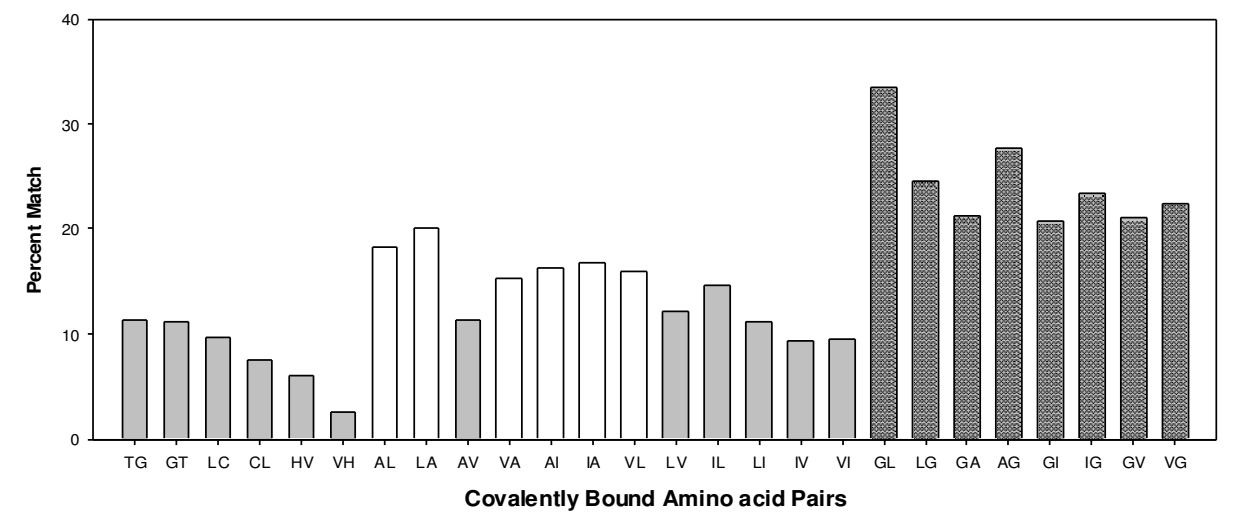




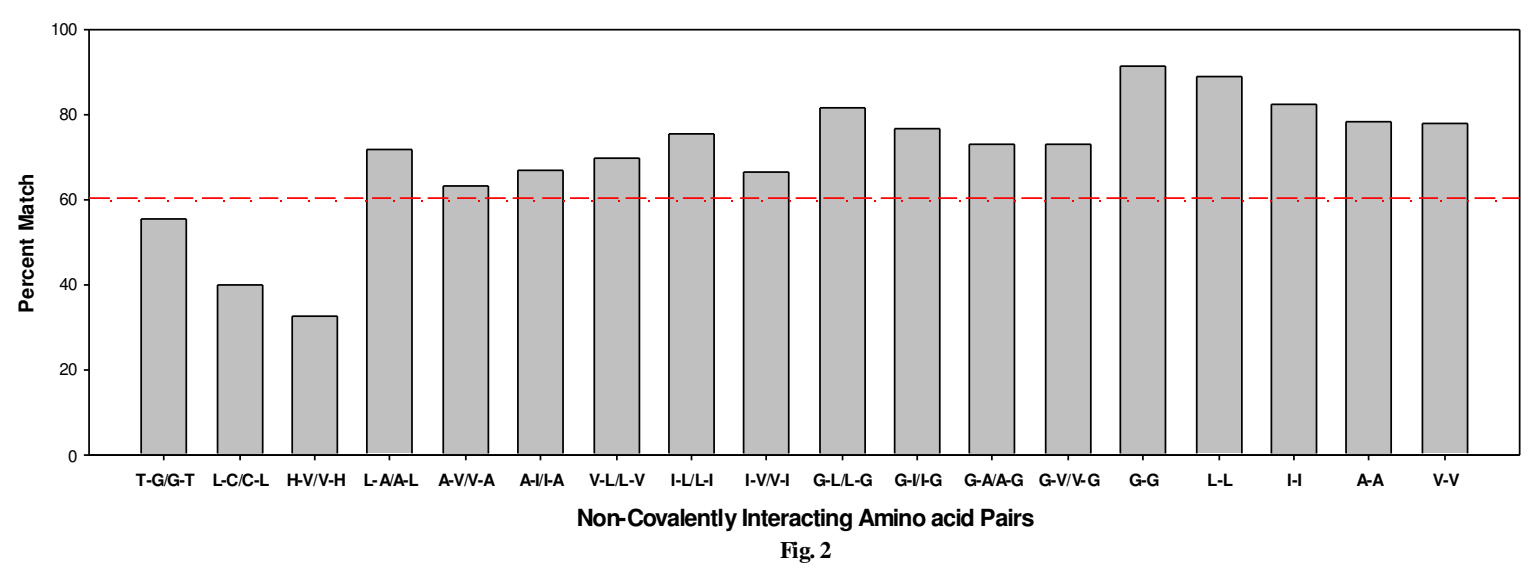

Figure 2: Representation of frequency of non-covalently linked amino acid pairs interacting through hydrophobic interactions in AMPs. The dashed red line indicates the threshold of $60 \%$ occurrence frequency in AMPs.

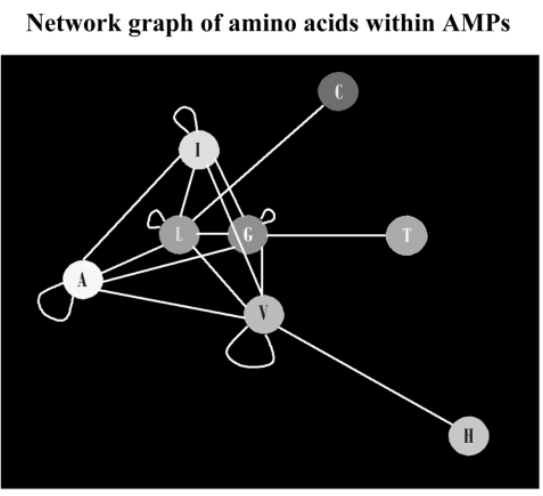

Figure 3: Network graph of frequently appearing amino acids within the primary sequence of AMPs. The amino acids (vertices) are denoted by their respective single letter codes and the connections (edges) between them denote their interaction. The distance between each amino acid pair is inversely proportional to its occurrence frequency within AMPs.

\section{References}

1. Barabasi, A.-L., Oltvai, Z.N., Network biology: understanding the cell's functional organization. Nature Reviews Genetics, 2004, 5, $101-114$.

2. Jeong, H., Mason, S.P., Barabasi, A.-L., lethality and centrality in protein networks. Nature, 2001, 411, $41-42$.

3. Manimaran, P., Hedge, S.R., Mande, S.C., Prediction of conditional gene essentiality through graph theoretical analysis of genome - wide functional linkages. Mol. Biol. Systems, 2009, 5, 1936 - 1942.

4. Jeong, H., Tombor, B., Albert, R., Oltvai, Z. N., Barabasi, A.-L., The large-scale organization of metabolic networks. Nature, 2000, 407, $651-654$.
5. Dobrin,R., Beg, Q.K., Barabasi, A-L., Oltavai,Z. N, Aggregation of topological motifs in Escherichia coli transcriptional regulatory network. BMC Bioinformatics, 2004, 5.

6. Alon, U., Introduction to Systems Biology: Design Principles of Biological Circuits. 2006, CRC, Boca Raton.

7. Davidson, E. H., The Regulatory Genome: Gene Regulatory Networks in Development And Evolution. 2006, Academic Press.

8. Levine, M., Davidson, E. H. Gene regulatory network for development. Proc. Nat. Acad. Sci. USA, 2005, 102, 4936 - 4942.

9. Thieffry, D., Huerta, A. M., Perez-Rueda, E., Collado-Vides, J., From specific gene 
10. regulation to genomic networks: a global analysis of transcriptional regulation in Escherichia coli. Bioessays, 1998, 20, 433 440.

11. Milo, R., Shen-Orr, S., Itzkovitz, S., Kashtan, N., Chklovskii, D., Alon, U., Network motifs: simple building blocks of complex networks. Science, 2002, 298, 824 827.

12. Alon, U., Network motifs: theory and experimental approaches. Nature Reviews Genetics, 2007, 8, $450-461$.

13. Shen-Orr, S., Milo, R., Mangan, S., Alon, U., Network motif in transcriptional regulation network of Escherichia coli. Nature Genetics, 2002, 31, $64-68$.

14. Mangan, S., Alon, U., Structure and function of the feed forward loop network motif. Proc. Nat. Acad. Sci. USA, 2003, 100, 11980-85.

15. Dobrin,R., Beg, Q.K., Barabasi, A-L., Oltavai,Z. N, Aggregation of topological motifs in Escherichia coli transcriptional regulatory network. BMC Bioinformatics, 2004, 5, doi:10.1186/1471-2 105-5-10.

16. Lotem-Yeger, E., Sattath, S., Khastan, N., Itzkovitz, S., milo, R., Pinter, R.Y., Alon, U., Margalit, H., Network motifs in integrated cellular networks of transcriptionregulation and protein-protein interaction. Proc. Nat. Acad. Sci USA, 2004, 101, 5934 5939.

17. Kashtan, N., Itzkovitz, S., Milo, R., Alon, U., Topological generalizations of network motifs. Phys. Rev. E, 2004, 70, doi: 10.1103/PhysRevE.70,031909.

18. Ifrah, D., Doisy, X., Ryge, T.S. and Hansen P.R., Structure-activity relationship study of anoplin. Jour. Pept. Sci. 2005, 11, 113-21.

19. Fontana, R., Mendes, M.A., de Souza, B.M., Konno, K., César, L.M.M., Malaspina, O., Palma M.A., Jelleines: a family of
20. antimicrobial peptides from the Royal Jelly of honeybees (Apis mellifera). Peptides. 2004, 25, 919-928.

21. Wu, M., Hancock, R., Improved Derivatives of Bactenecin, a Cyclic Dodecameric Antimicrobial Cationic Peptide. Antimicrob. Agents Chemother.1999, 43(5), 1274-6.

22. Giacometti, A., Cirioni, O., Riva, A., Kamysz, W., Silvestri, C., Nadolski, P., Vittoria, A.D., Lukasiak, J. and Scalise, G., In Vitro Activity of Aurein 1.2 Alone and in Combination with Antibiotics against GramPositive Nosocomial Cocci. Antimicrob. Agents Chemother. 2007, 51(4), 1494-96.

23. Dennison, S.R., Harris, F., Phoenix, D.A., Are Oblique Orientated a-Helices Used by Antimicrobial Peptides for Membrane Invasion? Prot. Pept. Lett. 2005, 12, 27-29.

24. Mandal, S.M., Dey, S., Mandal, M., Sarkar, S., Maria-Neto, S., Franco, O.L., Identification and structural insights of three novel antimicrobial peptides isolated from green coconut water. Peptides. 2009, 30, 233-237.

25. Giacometti, A., Cirioni, O., Kamysz, W., Silvestri, C., Licci, A., D’Amato, G., Nadolski, P., Riva, A., Lukasiak, J., Scalise, G., In Vitro Activity and Killing Effect of Uperin 3.6 against Gram-Positive Cocci Isolated from Immunocompromised Patients. Antimicrob. Agents Chemother. 2005,49(9), 3933-3936.

26. Kamysz, w., Nadolski,P., Antibacterial activity of peptides from amphibians skin. Ann. Acad. Med. Gedanensis. 2005,35, 2934.

27. Orive1, J., Redeker, v., Le Caer, J., Krieri, F., Revol-Junellesi, A., Longeon, A., Chaffotte, A., Dejean, A., Rossier, J. Ponericins, New Antibacterial and Insecticidal Peptides from the Venom of the Ant Pachycondyla goeldii. J. Biol. Chem. 2001, 276(21), 17823-9. 